\title{
Systems analysis of reform in Russia's energy industry
}

\author{
Stennikov Valery ${ }^{1}$, Golovshchikov Vladimir ${ }^{1, *}$ \\ ${ }^{1}$ Melentiev Energy Systems Institute, 130 Lermontov str., Irkutsk, Russia
}

\begin{abstract}
The paper presents the results of a systems analysis of the reform of Russia's electric power industry. The analysis has revealed the main problems of the industry and the causes behind them. It has also shown that many of the negative outcomes of the reform are due to the lack of a systems approach to the formulation of the reform goals and objectives and the assessment of their implementation consequences. The lack of a systems approach to crucial problems of the electric power industry in the context of the actual situation and the lack of reasonable development forecasts have led to directive management methods. This significantly reduces the efficiency of the development of the electric power industry in Russia in the medium and long term. The analysis allowed us to propose some priority measures that will not require fundamental changes in the electric power industry but can improve the situation in the medium term.
\end{abstract}

Keywords: reform of the electric power industry, wholesale and retail electricity and capacity market, concept, strategy, laws, models.

\section{Introduction}

The radical transformations of the entire economic, political and social system of the country, which began in Russia in the 1990s, also affected the national energy industry. They had an effect on the energy consumption towards its reduction, the level of functioning of systems, the economic viability of the industry, the changes in the forms of ownership, and influenced the quality and reliability of energy supply. Infrastructure industries, including energy machine-building, electrical engineering, and others, have undergone significant changes. The need to reform the electric power industry providing the country with electric and thermal energy became increasingly more pronounced over time. The reform was planned in the framework of the implementation of the law "On Electricity."

\section{Systems analysis of reform}

Currently, a systems analysis is required to examine the background conditions for the reform in the energy industry of the Russian Federation and the results of this process, identify the main negative points and their causes, and give some suggestions for eliminating the most acute problems. A similar analysis with varying depth of investigation was carried out repeatedly by representatives of the scientific and engineering community [1-9]. However, most of the analytical studies did not pay due attention to a systems approach to solving the problems of energy reforming in the Russian Federation both at the federal and regional levels, which include the interconnection of economic, financial, organizational, technological, and socio-political factors.
The theory of systems research was proposed and continues to be actively developed at Melentiev Energy Systems Institute (former Siberian Energy Institute) SB RAS. Its methodological toolkit is a systems approach that allows addressing the most crucial issues in the field of energy arising in the analysis, operation, and development of energy systems.

It is well known that the radical reform of the Russian power industry was initiated by the adoption of the Concept of the Strategy of RAO UES of Russia, which was called the 5+5 Concept (1998-2003 and 2003-2008) in the scientific and engineering community. The $5+5$ Concept primarily aimed at improving the financial and economic situation of JSC UES of Russia. Solving the most significant technical and technological problems was relegated to the background. Lack of a comprehensive approach was the first systems error in the process of reforming the industry. Criticism of the Concept by many representatives of the scientific and engineering community, including the Melentiev Energy Systems Institute SB RAS, made it possible to partially eliminate this error in the basic documents of the industry reform, i.e., the Decree of the Government of the Russian Federation No. 526-p "On Reform of the Electric Power Industry" (July 2001), Federal Law № 35-FL "On Electric Power Engineering" (2003), and in subsequent regulatory documents. These documents defined the avenues of the reform, its goals, and objectives. However, a systems assessment of the future impact of the reform targets implementation has not been carried out. The lack of such 
an assessment and analysis of the reform outcomes, despite some achievements in the power industry, led to the failure to accomplish the expected results.

The analysis of a range of problems in the field of electric power industry reform and the ongoing discussions on this issue revealed the most pressing issues that need to be solved and which many representatives of the scientific and engineering community agree with [1-9].

In a short form, some of the reform results for 2021 can be presented as follows [1-6,8,9].

1. According to the reform goals, a wholesale electricity and power market was created but it was characterized by insufficient efficiency. The full-fledged competition did not work out either in energy production or consumption. The major market "players" (energy companies, large consumers, and their shareholders) received the main advantages in the wholesale electricity market. This market created unequal financial and economic conditions for most CHPPs, which are forced to sell electricity in the wholesale electricity market at competitive prices, and supply heat energy to the retail markets at regulated rates. Moreover, the heat supply problems were not considered in the documents mentioned, although this is an essential component of the energy industry in our mainly northern country (more than a third of electricity output is also produced at thermal power plants). All this was recognized at the hearings in the State Duma of the Russian Federation in April 2017. Electrical and thermal energy has not become a full-fledged commodity (albeit socially significant) in the economic sense of this term.

2. There is still a significant "cross-subsidization" that contradicts market principles, both between groups of energy consumers and between territories. Even within the same vast area, electricity consumers connected to the grids at the same voltage level pay the same price for electricity transmission services, although they have to pay differentially, depending on the distance to power centers. The analysis shows that the preservation of "cross-subsidization" is primarily related to socio-political factors. As a result, in the Russian Federation, "cross-subsidization" is likely to persist in the long term (10-15 years). Effective state mechanisms to support low-income strata of the population with the gradual abandonment of "cross-subsidization" have not yet been created.

3. Competitive and efficient fuel markets for power plants, which would make it possible to influence the reduction of in the cost of electricity and heat produced, have not been created. Gazprom is an absolute monopolist in the Russian gas market. It is the main gas supplier for thermal power plants (TPPs) in the European part and the Urals of the Russian Federation, for which natural gas is the main fuel. The situation in the coal market is somewhat better, but some reasons limit the competition in this market.

4. The reform did not ensure the control of electricity and heat (capacity) tariffs (prices) growth for end consumers, and this growth often exceeds the inflation rate in the country. The reason for this is that the proposed measures to reduce the costs of generating, grid, and energy retail companies, as a basis for reducing tariffs (prices), in most cases do not provide the expected effect. The participants in the energy supply process often find reasons to increase their required gross revenue (RGR), which, as a rule, are accepted by the state energy regulatory authorities, explaining this by their obligation to ensure the reliability of the energy supply process.

5 . The analysis showed that at least half of the energy facilities had to be decommissioned due to their wear and tear. Introduction of mechanisms, such as Capacity Supply Agreements (CDA) and "CDA +" (for modernization of heat and power facilities), RAB-regulation (Regulatory Asset Base, conventional translation "fair return on investment") for the power grid facilities and the current tariff policy, gave some positive effect but did not result in a radical improvement in the situation. As a result, the electric power industry develops due to an increase in the financial burden on consumers, since the aforementioned mechanisms imply the return of financial resources to investors as a result of an increase in tariffs (prices) under government guarantees in a fairly short time. At the same time, market mechanisms, for example, bonds, shares, and others, are attracted to a minimum extent.

6 . The huge existing and continuously expanding legal and regulatory framework governing practically all relations in the electric power industry is complex and contradictory in some provisions. The set goals and objectives in various documents do not contribute to solving the pressing issues facing the energy industry. Some of them contradict each other. In general, they do not ensure the formulation and implementation of a targeted energy policy, which leads to a chaotic process of industry development.

7. The situation is significantly aggravated by the unsatisfactory law enforcement practice concerning some important legal documents. These include, for example, Federal Law No. 261-FZ "On increasing energy efficiency," according to which an objective picture of the energy-saving potential in the Russian Federation was to be obtained, but it was not. By mid-2012, all energy consumption facilities (except for gas consumers (by 2015) were to be equipped with metering devices, but this was not done either. A significant Order of the Government of the Russian Federation No. 511-r of 03.04, 2013, aimed at the efficient functioning and development of the power grid facilities, and, first of all, distribution low voltage power grids ( $35 \mathrm{kV}$ and below), which are becoming essential as a technological basis for retail energy markets, is also carried out extremely unsatisfactorily

The conducted systems analysis revealed the main reasons for many poor outcomes of the reform of the electric power industry in the Russian Federation.

1. The scientific and engineering community of the country has received practically no available information on in-depth analysis of the effectiveness of the planned base goals and objectives in Russia's context. It can be stated that no systems approach was applied to accomplish the most crucial objective for the country to reform the industry. A whole host of issues that fundamentally 
affect the future results of the industry reform have not been scrutinized. These include the technological structure of energy systems, the capacity and location of electricity generating facilities in the country, the conditions for fuel supply of energy sources, the climatic specifics of regions, problems of heat supply, and many more. A significant factor of the negative consequences of the energy industry reform is an almost complete rejection of the generally successful experience of its functioning and development in the USSR, which made it possible to create the energy industry, one of the most powerful in the world. Of course, the "Soviet" period also saw many problems in the energy industry (constraining local initiative, almost complete lack of material incentives to work effectively, strict state control, failure to fulfill the plans of the last two five-year periods, etc.) but the industry quite successfully performed its main task to reliably supply energy to consumers. It is also worth noting that the basic documents on the industry reform ignored the mentality of the Russian population that had been forming over the years, the majority of which had a negative attitude towards competition, market relations with free prices in any sphere, the redistribution of property in the 1990s, and others that led to social inequality, which is observed nowadays. At the same time, the developed "Western" countries successfully implement various forms of functioning and management of the electric power industry, including an effective combination of competitive principles and state regulation [10-13]. Moreover, the organization and functioning of the wholesale electricity and power market in Russia are currently based on the "British model," with more than $80 \%$ of electricity traded at the "day ahead" market. Currently, the UK has fundamentally changed this model, and now the market is based on bilateral agreements.

2. Having abandoned the planned economy, the reform did not offer anything effective for the management of the country's economic activity in return. Various concepts, strategies, and doctrines began to appear instead of thoroughly developed national plans. This process continues at present. Some of the aforementioned "documents" end with the so-called "road maps" (in fact, plans), which are not supported by reasonable real terms and resources, and which in most cases are not related to each other. It should be particularly noted that due to the lack of a purposeful systems approach in the formation of the next "strategy," the implementation of its main indicators, as a rule, lags far behind the planned one. This is also typical of the energy industry, for example: due to the obvious failure to achieve the main indicators of the Energy Strategy-2030 by 2020 , it had to be adjusted for the period until 2035. Fundamental errors (main indicators) in the implementation of energy policy in the Russian Federation are caused by large errors in forecasts of the country's socio-economic development, even in the short term (3-5 years), not to mention the longer term. It seems unlikely that the country's leadership when making decisions on strategic development makes fully informed decisions proposed by research organizations. Improper planning and optimistic forecasts of the socio- economic development of the Russian Federation cause an unreasonable overestimated prospective growth in energy consumption in the country. Focus on these indicators and the need to modernize and develop generating sources and power grids resulted in the emergence of at least $50 \mathrm{GW}$ of "excess" electric power and high voltage networks ( $220 \mathrm{kV}$ and more) with a load of no more than $15-20 \%$. The financial burden was transferred to consumers through the CDA and RAB regulation mechanisms. At the same time, for example, in the final price of electricity for consumers, the cost of services for the electricity transmission through the power grids, reached more than $60 \%$ on average in the Russian Federation, whereas in the USSR it was no more than $20 \%$, as it is now in developed countries.

3. The actual refusal to formulate carefully worked out plans for the development of all spheres of the country's life, unfortunately, has led to directive management in the economy and the energy industry as well. Probably, this is necessary for the social sphere due to the current situation in the country but the economy in general, and the energy industry in particular, this approach does not seem to be instrumental due to the lack of grounds for the decisions made and the haste to implement them. This can be exemplified by the expansion of the capacity of the Transsiberian railway and, first of all, that of the Baikal-Amur Railway, which did not take into account the technical possibilities for increasing the railroad traffic along the dam of the Bratsk hydroelectric power station or the prospective volumes of goods to be transported, and, first of all, coal [14]. Only in the middle of 2021, the Ministry of Energy of the Russian Federation supported the need to move the road and railroad from the dam of the Bratsk hydroelectric power station and construct a separate bridge across the Angara River for these traffic flows. A difficult situation is facing the implementation of the Eastern Gas Policy formulated in 2007. To a large extent, this also applies to the process of "digitalization" of the Russian economy in general and the electric power industry in particular, which was declared a "driver of the country's development" a few years ago. However, without the systems consideration of many factors, such as the state of the fixed assets in the energy industry, the principles of its management, foreign electronic components and software, and others, total "digitalization" can lead not only to an ineffective investment of funds but also to threats to the energy security of Russia [15].

4. Liquidation of JSC "UES of Russia", which controlled more than $70 \%$ of the country's electric power industry; the subsequent division of the industry into a large number of energy companies with different financial, economic, and technological indices; and the lack of real competition between the entities of the industry led to inefficient management of the country's electric power industry. Moreover, the energy industry begins to lose its infrastructure properties, gradually becoming an appendage of some industries and even individual large energy consumers (for example, the situation in the Irkutsk re- 
gion: the aluminum industry and the electric power industry). This is mainly because the Ministry of Energy of the Russian Federation did not become an effective center of competence and management of the electric power industry over the entire period of the industry reform. For many years, the main activity of the Ministry has been focused on the oil and gas industry (and especially the export of hydrocarbons), which provides the filling of the Russian budget.

5. Reasonable proposals of the scientific and engineering community on conceptual provisions, adjustments to strategies and plans, as well as on amendments to the regulatory framework aimed at eliminating bottlenecks in the electric power industry, which could have a positive effect in the short-term prospect, remain unclaimed. Many decisions, for example, by the federal legislative bodies, whose representatives are also involved in the discussion of problems, as a rule, end with another portion of "recommendations" providing no specific mechanisms for their implementation.

Unfortunately, at the Government level, there is no full-fledged document that would contain a systems analysis of the current situation in the electric power industry and the correction of previously made decisions for the further effective process of reforming the industry.

Analysis of the current situation in the power industry has shown that there are different opinions about the outcomes of the reform and what needs to be done in the future: 1) the reform had a positive effect, 2) it is necessary to completely revise the results and start the reform from the starting point, 3 ) the reform did not give positive results, it is necessary to return to the state-owned energy industry in the Russian Federation. There is also a fourth option. The main goals of the reform, which in principle were correct, were not achieved for various reasons, including those discussed above. But the reform must be continued eliminating its most problematic results, which are well known. To this end, it will be necessary to revise some conceptual provisions, update the existing strategy for the development of the industry and significantly adjust the acting legislative framework. A positive effect of such events can be achieved only with a systems approach that takes account of the problems facing both the energy industry and the related industries.

This option, in the opinion of the authors and many representatives of the scientific and engineering community, is the most preferable for the Russian Federation. It can have good prospects only with the active support by the federal and regional state bodies. Unfortunately, this has not yet been observed, and in the medium term, the first option from the above with elements of the third option will exist.

To implement the fourth option, it is advisable to consider some priority measures which could be used to commence the elimination of some "bottlenecks" in the functioning of the electric power industry and which have already been proposed at various events and in scientific and technical publications, for example, in [1-4, 8].
First of all, it is necessary to once again summarize the results of the electric power industry reform and make it in the form of an all-Russian discussion of the scientific and engineering community and representatives of government authorities, and create a working group to develop practical mandatory measures to eliminate the negative consequences of the industry reform $[1,2]$. The activities to be simultaneously started are:

1. Grant the right for all power plants to enter the wholesale electricity (power) market and the retail electricity (power) market. Calculations show that the sale of electricity generated by a CHP plant in the retail market can provide an economic effect for the industry of 20 $30 \%$.

2. Consolidate territorial (distribution) power grid companies based on the most efficient of them; this will also ensure a reduction in tariffs for the electricity transmission services of grid companies.

3. Enable the power grid companies, based on the economic feasibility of the regions, to sell electricity to consumers since there was no competition for consumers among the energy sales companies.

4. Start the creation of "Unified Retail Energy and Power Markets" in the regions, providing a positive effect for all participants in these markets. It is these markets where the majority of electric and thermal energy consumers operate [16].

5. Start the transformation of the "day-ahead market" mechanism of the wholesale electricity market into a balancing market. The bigger proportion of electricity must be traded under bilateral agreements at unregulated prices.

6. Develop and implement a methodology for tariff setting for the electricity transmission services through the networks, given the actual costs of such transmission to specific consumers. Test calculations have shown the economic feasibility of this approach.

7. Strengthen financial responsibility for the quality and reliability of energy supply, enshrined in the existing legal framework.

8. Stimulate grid companies to switch to $20 \mathrm{kV}$ instead of $10 \mathrm{kV}$, at least during new construction, which will solve many problems related to connecting new consumers to power grids.

9. Start the adoption of the cutting-edge technologies in the energy industry through pilot projects, given the physical condition of energy facilities, available resources, cybersecurity, and make a mandatory analysis of the implications of their implementation.

\section{Conclusion}

The analysis has shown that most goals and objectives of the electric power industry reform in Russia have not been achieved. This is because these goals and objectives, the methods of their achievement, and the expected effects have not been comprehensively analyzed. The effective development of the country's most essential industry requires a systems standpoint, the consideration of 
the existing constructive proposals to improve the situation in the electric power industry, also the consideration of modern challenges and threats to develop a new concept, an appropriate strategy and specific plans for its implementation. The available well-grounded proposals for the effective continuation of the reform can be implemented shortly (two to five years).

This work is carried out as part of the State Assignment Project (no. FWEU-754 2021-0001) of the Fundamental Research Program of Russian Federation 20212030, and with the support of the Russian Foundation for Basic Research, grant 019-010-00183

\section{References}

1. Kutovoy G.P. In need of a new paradigm (or architectonics) of economic relations in the electric power industry //Energetik. 2016. No. 2. pp. 8-13. (In Russian)

2. Kutovoy G.P. On the need to continue reforms in the electric power industry //Energoekspert. 2019. No. 3. pp. 18-25. (In Russian)

3. Stennikov V.A. On reforming heat supply in Russia //Energosberezhenie. 2014. No. pp. 63-66. (In Russian)

4. Stennikov V.A. On reforming heat supply in Russia (cont'd) //Energosberezhenie. 2014. No. 6. P. 62-67. (In Russian)

5. Belyaev L.S. Issues of the electric power market. Novosibirsk: Nauka, 2009. - 296 p.

6. Kozhukhovsky I.S. Key results of the electric power industry reform and new challenges //Regional'naya energetika i energosberezhenie. 2018. No. 4. pp. 8-15. (In Russian)

7. Zhilkina Yu.A. Issues of reforming the electric power industry in Russia // Energetik. 2020. No. 1. P. 2932. (In Russian)

8. Stennikov V.A., Golovshchikov V.O. Current issues and ways of transformation of the Russian electric power industry // Energetik. 2020. №6. pp. 3-9. (In Russian)

9. Foreign electric power industry. Association NP Market Council. Available at: https://www.npsr.ru/ru/market/cominfo/foreign/index.htm [accessed: 15.12.2020].

10. International experience in organizing electric power markets. Available at: www.bigpowernews.ru//research/document38893.phtml [accessed: 15.12.2020].

11. Foreign experience of reforming the electric power industry. Available at:

https://libertarium.ru/1_energy_kr_04 [accessed: 7.12.2020].

12. Korolev V.G. Russian and world experience in the formation of electricity and capacity markets. Dissertation for a candidate of economic sciences. Available at: libed.ru/knigi-nauka/529809-1-rossiyskiy-mirovoyopit-formirovaniya-rinkov-elektroenergii-moschnosti [accessed: 23.11].
13. Golovshchikov V.O., Ognev D.V., Petryakova E.A. Prospects for the BAM and Transsib, taking into account the state of the regions and the development of the coal industry // Energy policy. 2021. No. 2 (156). pp. 3042.

14. Golovshchikov V.O. Is the Russian electric power industry ready for the transition to a new technological platform based on mass digitalization? // Energetik. 2018. No. 11. pp. 3-6. (In Russian)

15. Stennikov V.A., Golovshchikov V.O. Electricity and heat retail market: challenges and development prospects // Energetik. 2019. No. 6. pp. 3-9. (In Russian) 